\title{
Convergence theorems of a new iteration for two nonexpansive mappings
}

Xueping Hou and Hongxia Du*

${ }^{\text {*Correspondence: }}$ duhongxia24@gmail.com College of Mathematics and Information Science, Henan Normal University, Henan, China

\begin{abstract}
The purpose of this paper is to introduce the following new general implicit iteration scheme for approximating the common fixed points of a pair of nonexpansive mappings in a uniformly convex Banach space: for any $x_{0} \in C$, the iterative process $\left\{x_{n}\right\}$ defined by $x_{n}=a_{n} x_{n-1}+b_{n} T y_{n}+c_{n} S x_{n}, y_{n}=a_{n}^{\prime} x_{n-1}+b_{n}^{\prime} x_{n}+c_{n}^{\prime} S x_{n-1}+d_{n}^{\prime} T x_{n}$, where $\left\{a_{n}\right\},\left\{b_{n}\right\},\left\{c_{n}\right\},\left\{a_{n}^{\prime}\right\},\left\{b_{n}^{\prime}\right\},\left\{c_{n}^{\prime}\right\},\left\{d_{n}^{\prime}\right\}$ are seven sequences of real numbers satisfying $a_{n}+b_{n}+c_{n}=1, a_{n}^{\prime}+b_{n}^{\prime}+c_{n}^{\prime}+d_{n}^{\prime}=1$, and $T, S: C \rightarrow C$ are two nonexpansive mappings. We approximate the common fixed points of these two mappings by weak and strong convergence of the scheme.
\end{abstract}

Keywords: nonexpansive mapping; common fixed points; weak and strong convergence; semicompact; condition $\left(A^{\prime}\right)$

\section{Introduction}

Let $C$ be a nonempty subset of a real Banach space $E$. A mapping $T$ of $C$ into itself is called nonexpansive if $\|T x-T y\| \leq\|x-y\|$ holds for all $x, y \in C$. We first recall the following two iterative processes due to Ishikawa [1] and Mann [2], respectively.

(I) Let $C$ be a nonempty convex subset of $E$ and let $T: C \rightarrow C$ be a mapping. For any given $x_{0} \in C$ the sequence $\left\{x_{n}\right\}$ defined by

$$
\begin{aligned}
& x_{n+1}=\left(1-a_{n}\right) x_{n}+a_{n} T y_{n}, \\
& y_{n}=\left(1-b_{n}\right) x_{n}+b_{n} T x_{n}, \quad n \geq 0,
\end{aligned}
$$

is called the Ishikawa iteration sequence, where $\left\{a_{n}\right\}$ and $\left\{b_{n}\right\}$ are two real sequences in $[0,1]$ satisfying some conditions. In particular, if $b_{n}=0$ for all $n \geq 0$, then $\left\{x_{n}\right\}$ defined by

$$
x_{0} \in C, \quad x_{n+1}=\left(1-a_{n}\right) x_{n}+a_{n} T x_{n}, \quad n \geq 0,
$$

is called the Mann iteration sequence.

In [3], Liu introduced the concepts of Ishikawa and Mann iterative processes with errors as follows.

(II) For a nonempty subset $C$ of a Banach space $E$ and a mapping $T: C \rightarrow C$, the sequence $\left\{x_{n}\right\}$ defined by

$$
\begin{aligned}
& x_{0} \in C, \quad x_{n+1}=\left(1-a_{n}\right) x_{n}+a_{n} T y_{n}+u_{n}, \\
& y_{n}=\left(1-b_{n}\right) x_{n}+b_{n} T x_{n}+v_{n}, \quad n \geq 0,
\end{aligned}
$$


where $\left\{u_{n}\right\}$ and $\left\{v_{n}\right\}$ are two summable sequences in $E$. In particular, if $b_{n}=0, v_{n}=0$, the sequence $\left\{x_{n}\right\}$ is called the Mann iteration sequence with errors.

Unfortunately, the definitions of Liu, which depend on the convergence of the error terms, are against the randomness of errors. Xu [4] studied the following new iteration process.

(III) Let $C$ be a nonempty convex subset of $E$ and let $T: C \rightarrow C$ be a mapping. For any given $x_{0} \in C$ the sequence $\left\{x_{n}\right\}$ defined by

$$
\begin{aligned}
& x_{n+1}=a_{n} x_{n}+b_{n} T y_{n}+c_{n} u_{n}, \\
& y_{n}=a_{n}^{\prime} x_{n}+b_{n}^{\prime} T x_{n}+c_{n}^{\prime} v_{n}, \quad n \geq 0,
\end{aligned}
$$

is called the Ishikawa iteration sequence with errors. Here $\left\{u_{n}\right\}$ and $\left\{v_{n}\right\}$ are two bounded sequences in $C$ and $\left\{a_{n}\right\},\left\{b_{n}\right\},\left\{c_{n}\right\},\left\{a_{n}^{\prime}\right\},\left\{b_{n}^{\prime}\right\},\left\{c_{n}^{\prime}\right\}$ are six sequences in $[0,1]$ satisfying the following conditions: $a_{n}+b_{n}+c_{n}=1, a_{n}^{\prime}+b_{n}^{\prime}+c_{n}^{\prime}=1, n \geq 1$. In particular, if $b_{n}^{\prime}=0, c_{n}^{\prime}=0$, the sequence $\left\{x_{n}\right\}$ is called the Mann iteration sequence with errors. Chidume and Moore [5] studied the above schemes in 1999.

A generalization of Mann and Ishikawa iterative schemes was given by Das and Debata [6] and Takahashi and Tamura [7]. This scheme dealt with two mappings: $x_{0} \in C$

$$
\begin{aligned}
& x_{n}=a_{n} x_{n-1}+\left(1-a_{n}\right) T y_{n-1}, \\
& y_{n-1}=b_{n} x_{n-1}+\left(1-b_{n}\right) S x_{n-1}, \quad n \geq 1 .
\end{aligned}
$$

Recently Khan and Fukhar [8] considered the above iterative process with bounded errors. In the present paper, we consider the following scheme:

$$
\begin{aligned}
& x_{0} \in C, \\
& x_{n}=a_{n} x_{n-1}+b_{n} T y_{n}+c_{n} S x_{n}, \\
& y_{n}=a_{n}^{\prime} x_{n-1}+b_{n}^{\prime} x_{n}+c_{n}^{\prime} S x_{n-1}+d_{n}^{\prime} T x_{n}, \quad n \geq 1,
\end{aligned}
$$

where $\left\{a_{n}\right\},\left\{b_{n}\right\},\left\{c_{n}\right\},\left\{a_{n}^{\prime}\right\},\left\{b_{n}^{\prime}\right\},\left\{c_{n}^{\prime}\right\},\left\{d_{n}^{\prime}\right\}$ are seven sequences of real numbers in $[0,1]$ satisfying $a_{n}+b_{n}+c_{n}=1, a_{n}^{\prime}+b_{n}^{\prime}+c_{n}^{\prime}+d_{n}^{\prime}=1$, and $T, S: C \rightarrow C$ are two nonexpansive mappings. Recently, some authors discuss similar issues (for example, please refer to [911]).

Approximating fixed points is an important subject in the theory of nonexpansive mappings and its applications in numerous applied areas. One is the convergence of iteration schemes constructed through nonexpansive mappings. In this paper, we study the iterative scheme given in (1) for weak and strong convergence for a pair of nonexpansive mappings in a uniformly convex Banach space. Before our discussions, we first recall the following definitions.

A Banach space $E$ is said to satisfy Opial's condition if whenever $\left\{x_{n}\right\}$ is a sequence in $E$ which converges weakly to $x$, then

$$
\liminf _{n \rightarrow \infty}\left\|x_{n}-x\right\|<\liminf _{n \rightarrow \infty}\left\|x_{n}-y\right\| \quad \text { for all } y \in E, y \neq x
$$


It is well known that every Hilbert space satisfies the Opial condition (see for example [12]).

A mapping $T$ is said to be semicompact (see, e.g., [13]) if for any sequence $\left\{x_{n}\right\}_{n=1}^{\infty}$ in $C$ such that $\lim _{n \rightarrow \infty}\left\|x_{n}-T x_{n}\right\|=0$, there exists a subsequence $\left\{x_{n_{j}}\right\}_{j=1}^{\infty}$ of $\left\{x_{n}\right\}_{n=1}^{\infty}$ such that $\left\{x_{n_{j}}\right\}_{j=1}^{\infty}$ converges strongly to some $u \in C$.

A mapping $T$ with domain $D(T)$ and range $R(T)$ in $E$ is said to be demiclosed at a point $p \in E$ if whenever $\left\{x_{n}\right\}$ is as sequence in $D(T)$ such that $\left\{x_{n}\right\}$ converges weakly to $x \in D(T)$ and $\left\{T x_{n}\right\}$ converges strongly to $p$, then $T x=p$.

We shall make use of the following results.

Lemma 1.1 [14] Let $\left\{s_{n}\right\},\left\{t_{n}\right\}$ be two sequences of nonnegative real numbers satisfying

$$
s_{n+1} \leq s_{n}+t_{n} \quad \forall n \geq 1
$$

(a) If $\sum_{n=1}^{\infty} t_{n}<\infty$, then $\lim _{n \rightarrow \infty} s_{n}$ exists.

(b) If $\sum_{n=1}^{\infty} t_{n}<\infty$ and $\left\{s_{n}\right\}$ has a subsequence converging to zero, then $\lim _{n \rightarrow \infty} s_{n}=0$.

Lemma 1.2 [15] Let E be a uniformly convex Banach space satisfying Opial's condition and let $C$ be a nonempty closed convex subset of $E$. Let $T$ be a nonexpansive mapping of $C$ into itself. Then $I-T$ is demiclosed with respect to zero.

Lemma 1.3 [16] Suppose that $E$ is a uniformly convex Banach space and $0<p \leq t_{n} \leq q<1$ for all positive integers $n$. Also suppose that $\left\{x_{n}\right\}$ and $\left\{y_{n}\right\}$ are two sequences of $E$ such that $\limsup _{n \rightarrow \infty}\left\|x_{n}\right\| \leq r, \limsup _{n \rightarrow \infty}\left\|y_{n}\right\| \leq r$ and $\limsup _{n \rightarrow \infty}\left\|t_{n} x_{n}+\left(1-t_{n}\right) y_{n}\right\|=r$ hold for some $r \geq 0$. Then $\lim _{n \rightarrow \infty}\left\|x_{n}-y_{n}\right\|=0$.

\section{Main results}

We first give the following key lemma.

Lemma 2.1 Let $E$ be a real uniformly convex Banach space and $C$ its nonempty convex subset. Let $T, S: C \rightarrow C$ be nonexpansive mappings. Let $\left\{x_{n}\right\}$ be the sequence as defined in (1) with the following conditions:

(1) $a_{n} \rightarrow 0, a_{n}^{\prime} \rightarrow 0, b_{n}^{\prime} \rightarrow 0$, as $n \rightarrow \infty$;

(2) $b_{n}, c_{n}, c_{n}^{\prime}, d_{n}^{\prime} \in[\delta, 1-\delta]$ for some $\delta \in(0,1)$;

(3) $c_{n}^{\prime}+d_{n}^{\prime} \leq \gamma$ for some $\gamma \in(0,1)$.

If $F:=F(T) \cap F(S) \neq \emptyset$, then we have

(i) $\lim _{n \rightarrow \infty}\left\|x_{n}-p\right\|$ exists for all $p \in F$ and $\left\{x_{n}\right\},\left\{T x_{n}\right\}$ and $\left\{S x_{n}\right\}$ are all bounded;

(ii) $\lim _{n \rightarrow \infty}\left\|x_{n}-T x_{n}\right\|=0=\lim _{n \rightarrow \infty}\left\|x_{n}-S x_{n}\right\|$.

Proof For any $p \in F$, we have

$$
\begin{aligned}
\left\|x_{n}-p\right\| & =\left\|a_{n}\left(x_{n-1}-p\right)+b_{n}\left(T y_{n}-p\right)+c_{n}\left(S x_{n}-p\right)\right\| \\
& \leq a_{n}\left\|x_{n-1}-p\right\|+b_{n}\left\|T y_{n}-p\right\|+c_{n}\left\|S x_{n}-p\right\| \\
& \leq a_{n}\left\|x_{n-1}-p\right\|+b_{n}\left\|y_{n}-p\right\|+c_{n}\left\|x_{n}-p\right\| .
\end{aligned}
$$


However, as the proof of the above inequality, it follows that

$$
\begin{aligned}
\left\|y_{n}-p\right\| & =\left\|a_{n}^{\prime}\left(x_{n-1}-p\right)+b_{n}^{\prime}\left(x_{n}-p\right)+c_{n}^{\prime}\left(S x_{n-1}-p\right)+d_{n}^{\prime}\left(T x_{n}-p\right)\right\| \\
& \leq a_{n}^{\prime}\left\|x_{n-1}-p\right\|+b_{n}^{\prime}\left\|x_{n}-p\right\|+c_{n}^{\prime}\left\|S x_{n-1}-p\right\|+d_{n}^{\prime}\left\|T x_{n}-p\right\| \\
& \leq a_{n}^{\prime}\left\|x_{n-1}-p\right\|+b_{n}^{\prime}\left\|x_{n}-p\right\|+c_{n}^{\prime}\left\|x_{n-1}-p\right\|+d_{n}^{\prime}\left\|x_{n}-p\right\| .
\end{aligned}
$$

Thus from (2) and (3), it is easy to check

$$
\left\|x_{n}-p\right\| \leq\left[a_{n}+b_{n}\left(a_{n}^{\prime}+c_{n}^{\prime}\right)\right]\left\|x_{n-1}-p\right\|+\left[c_{n}+b_{n}\left(b_{n}^{\prime}+d_{n}^{\prime}\right)\right]\left\|x_{n}-p\right\|,
$$

which implies that

$$
\left\|x_{n}-p\right\| \leq\left\|x_{n-1}-p\right\|
$$

and the limit $\lim _{n \rightarrow \infty}\left\|x_{n}-p\right\|$ exists for all $p \in F$. Furthermore $\left\{x_{n}\right\}$ is bounded and $\left\{S x_{n}\right\}$ and $\left\{T x_{n}\right\}$ are both bounded also. Now suppose $\lim _{n \rightarrow \infty}\left\|x_{n}-p\right\|=c$ for some $c \geq 0$. By the inequalities (3) and (5), we have

$$
\limsup _{n \rightarrow \infty}\left\|y_{n}-p\right\| \leq c
$$

From the iterative process (1), we have

$$
\left\|x_{n}-p\right\|=\left\|b_{n}\left[T y_{n}-p+a_{n}\left(x_{n-1}-S x_{n}\right)\right]+\left(1-b_{n}\right)\left[S x_{n}-p+a_{n}\left(x_{n-1}-S x_{n}\right)\right]\right\| .
$$

Since $a_{n} \rightarrow 0,\left\{x_{n}\right\},\left\{S x_{n}\right\}$ are both bounded and (6), it follows from Lemma 1.3 that

$$
\lim _{n \rightarrow \infty}\left\|T y_{n}-S x_{n}\right\|=0
$$

Next, by the inequality (2) and (5), we have

$$
\begin{aligned}
\left\|x_{n}-p\right\| & \leq a_{n}\left\|x_{n-1}-p\right\|+b_{n}\left\|y_{n}-p\right\|+c_{n}\left\|x_{n}-p\right\| \\
& \leq a_{n}\left\|x_{n-1}-p\right\|+b_{n}\left\|y_{n}-p\right\|+c_{n}\left\|x_{n-1}-p\right\| \\
& =\left\|x_{n-1}-p\right\|+b_{n}\left(\left\|y_{n}-p\right\|-\left\|x_{n-1}-p\right\|\right),
\end{aligned}
$$

which means

$$
\frac{\left\|x_{n}-p\right\|-\left\|x_{n-1}-p\right\|}{b_{n}}+\left\|x_{n-1}-p\right\| \leq\left\|y_{n}-p\right\| .
$$

Taking liminf on both sides in the above inequality and by (6) and $b_{n} \in[\delta, 1-\delta]$ for some $\delta \in(0,1)$, we have

$$
c \leq \liminf _{n \rightarrow \infty}\left\|y_{n}-p\right\| \leq \limsup _{n \rightarrow \infty}\left\|y_{n}-p\right\| \leq c,
$$

which yields

$$
\lim _{n \rightarrow \infty}\left\|y_{n}-p\right\|=c .
$$


It is easy to see that

$$
\begin{aligned}
\left\|y_{n}-p\right\|= & \| c_{n}^{\prime}\left[S x_{n-1}-p+a_{n}^{\prime}\left(x_{n-1}-T x_{n}\right)+b_{n}^{\prime}\left(x_{n}-T x_{n}\right)\right] \\
& +\left(1-c_{n}^{\prime}\right)\left[T x_{n}-p+a_{n}^{\prime}\left(x_{n-1}-T x_{n}\right)+b_{n}^{\prime}\left(x_{n}-T x_{n}\right)\right] \| .
\end{aligned}
$$

Since $a_{n}^{\prime} \rightarrow 0, b_{n}^{\prime} \rightarrow 0,\left\{S x_{n}\right\}$ and $\left\{T x_{n}\right\}$ are both bounded, then by Lemma 1.3 we have

$$
\lim _{n \rightarrow \infty}\left\|S x_{n-1}-T x_{n}\right\|=0
$$

Moreover, by the iterative process (1) again, we get

$$
\left\|x_{n}-T y_{n}\right\| \leq a_{n}\left\|x_{n-1}-T y_{n}\right\|+c_{n}\left\|S x_{n}-T y_{n}\right\|,
$$

which, by $a_{n} \rightarrow 0$ as $n \rightarrow \infty$ and (8), implies that

$$
\lim _{n \rightarrow \infty}\left\|x_{n}-T y_{n}\right\|=0
$$

Hence from (8) and (13), we have

$$
\left\|x_{n}-S x_{n}\right\| \leq\left\|x_{n}-T y_{n}\right\|+\left\|T y_{n}-S x_{n}\right\| \rightarrow 0
$$

as $n \rightarrow \infty$. Note that

$$
\begin{aligned}
\left\|y_{n}-x_{n}\right\| & =\left\|a_{n}^{\prime}\left(x_{n-1}-x_{n}\right)+c_{n}^{\prime}\left(S x_{n-1}-x_{n}\right)+d_{n}^{\prime}\left(T x_{n}-x_{n}\right)\right\| \\
& \leq a_{n}^{\prime}\left\|x_{n-1}-x_{n}\right\|+c_{n}^{\prime}\left\|S x_{n-1}-T x_{n}\right\|+c_{n}^{\prime}\left\|T x_{n}-x_{n}\right\|+d_{n}^{\prime}\left\|T x_{n}-x_{n}\right\| ;
\end{aligned}
$$

then it follows from the above inequality that

$$
\begin{aligned}
\left\|x_{n}-T x_{n}\right\| \leq & \left\|x_{n}-S x_{n}\right\|+\left\|S x_{n}-T y_{n}\right\|+\left\|T y_{n}-T x_{n}\right\| \\
\leq & \left\|x_{n}-S x_{n}\right\|+\left\|S x_{n}-T y_{n}\right\|+\left\|y_{n}-x_{n}\right\| \\
\leq & \left\|x_{n}-S x_{n}\right\|+\left\|S x_{n}-T y_{n}\right\|+a_{n}^{\prime}\left\|x_{n-1}-x_{n}\right\| \\
& +c_{n}^{\prime}\left\|S x_{n-1}-T x_{n}\right\|+c_{n}^{\prime}\left\|T x_{n}-x_{n}\right\|+d_{n}^{\prime}\left\|T x_{n}-x_{n}\right\| .
\end{aligned}
$$

That is to say,

$$
\begin{aligned}
& \left\|x_{n}-T x_{n}\right\| \\
& \quad \leq \frac{1}{1-\gamma}\left\{\left\|x_{n}-S x_{n}\right\|+\left\|S x_{n}-T y_{n}\right\|+a_{n}^{\prime}\left\|x_{n-1}-x_{n}\right\|+c_{n}^{\prime}\left\|S x_{n-1}-T x_{n}\right\|\right\},
\end{aligned}
$$

which, from (8), (12), (14), and $a_{n}^{\prime} \rightarrow 0$, means that

$$
\lim _{n \rightarrow \infty}\left\|x_{n}-T x_{n}\right\|=0
$$

The proof of the lemma is completed.

Now we give the weak convergence first. 
Theorem 2.2 Let E be a uniformly convex Banach space satisfying Opial's condition and $C, S, T$, and $\left\{x_{n}\right\}$ be as taken in Lemma 2.1. If $F:=F(T) \cap F(S) \neq \emptyset$, then $\left\{x_{n}\right\}$ converges weakly to a common fixed point of $S$ and $T$.

Proof Let $p \in F$. As the proof of Lemma 2.1, $\lim _{n \rightarrow \infty}\left\|x_{n}-p\right\|$ exists. Since $E$ is uniformly convex, every bounded subset of $E$ is weakly compact, so that there exists a subsequence $\left\{x_{n_{k}}\right\}$ of the bounded sequence $\left\{x_{n}\right\}$ such that $\left\{x_{n_{k}}\right\}$ converges weakly to a point $q \in C$. Therefore, it follows from (ii) in Lemma 2.1 that

$$
\lim _{k \rightarrow \infty}\left\|T x_{n_{k}}-x_{n_{k}}\right\|=0
$$

By Lemma 1.2, we know $I-T$ is demiclosed, then it is easy to see that $q \in F(T)$. With a similar proof, it follows that $q \in F(S)$ also. Next we prove uniqueness. Suppose that this is not true, then there must exist a subsequence $\left\{x_{n_{j}}\right\} \subset\left\{x_{n}\right\}$ such that $\left\{x_{n_{j}}\right\}$ converges weakly to another $q^{*} \in C$ and $q^{*} \neq q$. Then by the same method given above, we can also prove $q^{*} \in F(T) \cap F(S)$.

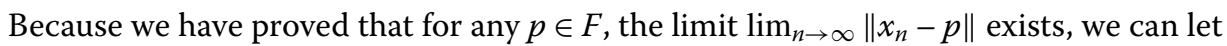

$$
\lim _{n \rightarrow \infty}\left\|x_{n}-q\right\|=d_{1}, \quad \lim _{n \rightarrow \infty}\left\|x_{n}-q^{*}\right\|=d_{2} .
$$

By the Opial condition of $E$, we have

$$
\begin{aligned}
d_{1} & =\limsup _{k \rightarrow \infty}\left\|x_{n_{k}}-q\right\|<\limsup _{k \rightarrow \infty}\left\|x_{n_{k}}-q^{*}\right\|=d_{2} \\
& =\limsup _{j \rightarrow \infty}\left\|x_{n_{j}}-q^{*}\right\|<\limsup _{j \rightarrow \infty}\left\|x_{n_{j}}-q\right\|=d_{1} .
\end{aligned}
$$

This is a contradiction, hence $q=q^{*}$. This implies that $\left\{x_{n}\right\}$ converges weakly to a common fixed point of $S$ and $T$.

Next we give several strong convergence results.

Theorem 2.3 Let $E$ be a uniformly convex Banach space and $C,\left\{x_{n}\right\}$ be as taken in Lemma 2.1. If one of the nonexpansive mappings $T$ and $S$ is semicompact and $F:=F(T) \cap$ $F(S) \neq \emptyset$, then $\left\{x_{n}\right\}$ converges strongly to a common fixed point of $S$ and $T$.

Proof Since one of $T$ and $S$ is semicompact and by (ii) in Lemma 2.1, then there exists a subsequence $\left\{x_{n_{j}}\right\}_{j=1}^{\infty}$ of the sequence $\left\{x_{n}\right\}_{n=1}^{\infty}$ such that $\left\{x_{n_{j}}\right\}_{j=1}^{\infty}$ converges strongly to $u$. Since $C$ is closed, $u \in C$. Continuity of $S$ and $T$ gives $\left\|S x_{n_{j}}-S u\right\| \rightarrow 0$ and $\left\|T x_{n_{j}}-T u\right\| \rightarrow 0$ as $n_{j} \rightarrow \infty$. Then by Lemma 2.1,

$$
\|S u-u\|=0=\|T u-u\| .
$$

This yields $u \in F$. By Lemma 2.1 again, $\lim _{n \rightarrow \infty}\left\|x_{n}-p\right\|$ exists for all $p \in F$, therefore $\left\{x_{n}\right\}$ must itself converge to $u \in F$. This completes the proof.

Recall that a mapping $T: C \rightarrow C$, where $C$ is a subset of $E$, is said to satisfy condition $(A)$ if there exists a nondecreasing function $f:[0, \infty) \rightarrow[0, \infty)$ with $f(0)=0, f(r)>0$ for all 
$r \in(0, \infty)$ such that $\|x-T x\| \geq f(d(x, F(T)))$ for all $x \in C$ where $d(x, F(T))=\inf \left\{\left\|x-x^{*}\right\|:\right.$ $\left.x^{*} \in F(T)\right\}$.

In [17], Senter and Dotson approximated fixed points of a nonexpansive mapping $T$ by Mann iteration. Recently Maiti and Ghosh [18] and Tan and Xu [14] considered the approximation of fixed points of a nonexpansive mapping $T$ by Ishikawa iteration under the same condition $(A)$ which is weaker than the requirement that $T$ is semicompact. Khan and Fukhar [8] modified this condition for two mappings $S, T: C \rightarrow C$ as follows.

Let $C$ be a subset of a Banach space $E$. Two mappings $S, T: C \rightarrow C$ are said to satisfy condition $\left(A^{\prime}\right)$ if there exists a nondecreasing function $f:[0, \infty) \rightarrow[0, \infty)$ with $f(0)=0$, $f(r)>0$ for all $r \in(0, \infty)$ such that $\frac{1}{2}(\|x-T x\|+\|x-S x\|) \geq f(d(x, F))$ for all $x \in K$, where $d(x, F)=\inf \left\{\left\|x-x^{*}\right\|: x^{*} \in F=F(T) \cap F(S)\right\}$.

Note that condition $\left(A^{\prime}\right)$ reduces to condition $(A)$ when $S=T$. We use condition $\left(A^{\prime}\right)$ to study the strong convergence of $\left\{x_{n}\right\}$ defined in (1).

Theorem 2.4 Let $E$ be a uniformly convex Banach space and $C,\left\{x_{n}\right\}$ be as taken in Lemma 2.1. Let $T, S$ satisfy the condition $\left(A^{\prime}\right)$ and $F:=F(T) \cap F(S) \neq \emptyset$, then $\left\{x_{n}\right\}$ converges strongly to a common fixed point of $S$ and $T$.

Proof By Lemma 2.1, $\lim _{n \rightarrow \infty}\left\|x_{n}-x^{*}\right\|$ exists for all $x^{*} \in F=F(T) \cap F(S)$. Let it be $c$ for some $c \geq 0$. If $c=0$, there is nothing to prove. Suppose $c>0$. By Lemma 2.1, $\lim _{n \rightarrow \infty} \| x_{n}-$ $T x_{n}\left\|=0=\lim _{n \rightarrow \infty}\right\| x_{n}-S x_{n} \|$. Moreover, from (4), we have $\left\|x_{n}-x^{*}\right\| \leq\left\|x_{n-1}-x^{*}\right\|$ which gives

$$
\inf _{x^{*} \in F}\left\|x_{n}-x^{*}\right\| \leq \inf _{x^{*} \in F}\left\|x_{n}-x^{*}\right\|
$$

That is to say, $d\left(x_{n}, F\right) \leq d\left(x_{n-1}, F\right)$ shows that $\lim _{n \rightarrow \infty} d\left(x_{n}, F\right)$ exists by virtue of Lemma 1.1. Now by condition $\left(A^{\prime}\right), \lim _{n \rightarrow \infty} f\left(d\left(x_{n}, F\right)\right)=0$. By the properties of $f$, therefore $\lim _{n \rightarrow \infty} d\left(x_{n}, F\right)=0$. Next we can take a subsequence $\left\{x_{n_{j}}\right\}$ of $\left\{x_{n}\right\}$ and $\left\{y_{j}\right\} \subset F$ such that $\left\|x_{n_{j}}-y_{j}\right\|<2^{-j}$. Then following the method of proof of Tan and Xu [14], we find that $\left\{y_{j}\right\}$ is a Cauchy sequence in $F$ and so it converges. Let $y_{j} \rightarrow y$. Since $F$ is closed, therefore $y \in F$ and then $x_{n_{j}} \rightarrow y$. As $\lim _{n \rightarrow \infty}\left\|x_{n}-x^{*}\right\|$ exists, $x_{n} \rightarrow y \in F$. This completes the proof.

Remark 2.5 From the proof of the above results, it is easy to see that we can extend our theorems to the iterative process (1) with errors as follows: let $C$ be a bounded closed convex subset of $E$ and the sequence $\left\{x_{n}\right\}$ be defined by

$$
\begin{aligned}
& x_{0} \in C, \\
& x_{n}=a_{n} x_{n-1}+b_{n} T y_{n}+c_{n} S x_{n}+e_{n} u_{n}, \\
& y_{n}=a_{n}^{\prime} x_{n-1}+b_{n}^{\prime} x_{n}+c_{n}^{\prime} S x_{n-1}+d_{n}^{\prime} T x_{n}+e_{n}^{\prime} v_{n}
\end{aligned}
$$

where $\left\{a_{n}\right\},\left\{b_{n}\right\},\left\{c_{n}\right\},\left\{e_{n}\right\},\left\{a_{n}^{\prime}\right\},\left\{b_{n}^{\prime}\right\},\left\{c_{n}^{\prime}\right\},\left\{d_{n}^{\prime}\right\},\left\{e_{n}^{\prime}\right\}$, are sequences in $[0,1]$ with $a_{n}+b_{n}+$ $c_{n}+e_{n}=1, a_{n}^{\prime}+b_{n}^{\prime}+c_{n}^{\prime}+d_{n}^{\prime}+e_{n}^{\prime}=1$ and $T, S: C \rightarrow C$ are both nonexpansive mappings, $\left\{u_{n}\right\},\left\{v_{n}\right\} \in C$. 


\section{Competing interests}

The authors declare that they have no competing interests.

\section{Authors' contributions}

All authors contributed equally to the manuscript, read and approved the final manuscript.

\section{Acknowledgements}

The authors are very grateful to the referees for their critical and valuable comments, which allowed us to improve the presentation of this article.

\section{Received: 29 November 2013 Accepted: 7 February 2014 Published: 19 Feb 2014}

\section{References}

1. Ishikawa, S: Fixed point and iteration of a nonexpansive mapping in a Banach spaces. Proc. Am. Math. Soc. 73, 65-71 (1976)

2. Mann, WR: Mean value methods in iteration. Proc. Am. Math. Soc. 4, 506-510 (1953)

3. Liu, LS: Ishikawa and Mann iterative process with errors for nonlinear strongly accretive mappings in Banach spaces. J. Math. Anal. Appl. 194, 114-125 (1995)

4. Xu, YG: Ishikawa and Mann iteration process with errors for nonlinear strongly accretive operator equations. J. Math. Anal. Appl. 224, 91-101 (1998)

5. Chidume, CE, Moore, C: Fixed point iteration for pseudocontractive maps. Proc. Am. Math. Soc. 127(4), 1163-1170 (1999)

6. Das, G, Debata, JP: Fixed points of quasi-nonexpansive mappings. Indian J. Pure Appl. Math. 17, 1263-1269 (1986)

7. Takahashi, W, Tamura, T: Convergence theorems for a pair of nonexpansive mappings. J. Convex Anal. 5(1), 45-58 (1998)

8. Khan, $\mathrm{SH}$, Fukhar-ud-din, H: Weak and strong convergence of a scheme with errors for two nonexpansive mappings. Proc. Am. Math. Soc. 61(8), 1295-1301 (2005)

9. Kim, GE: Weak and strong convergence for quasi-nonexpansive mappings in Banach spaces. Bull. Korean Math. Soc 49(4), 799-813 (2012)

10. Zhang, F, Zhang, H, Zhang, YL: New iterative algorithm for two infinite families of multivalued quasi-nonexpansive mappings in uniformly convex Banach spaces. J. Appl. Math. 2013, Article ID 649537 (2013)

11. Zhang, JL, Su, YF, Cheng, QQ: Strong convergence theorems for a common fixed point of two countable families of relatively quasi nonexpansive mappings and applications. Abstr. Appl. Anal. 2012, Article ID 956950 (2012)

12. Opial, Z: Weak convergence of successive approximations for nonexpansive mappings. Bull. Am. Math. Soc. 73 591-597 (1967)

13. Sun, $\mathrm{ZH}$ : Strong convergence of an implicit iteration process for a finite family of asymptotically quasinonexpansive mappings. J. Math. Anal. Appl. 286, 351-358 (2003)

14. Tan, KK, Xu, HK: Approximating fixed points of nonexpansive mappings by the Ishikawa iteration process. J. Math. Anal. Appl. 178, 301-308 (1993)

15. Browder, FE: Nonlinear operators and nonlinear equations of evolution in Banach spaces. In: Proceedings of the Symposium on Pure Mathematics, vol. 18 (1976)

16. Schu, J: Weak and strong convergence to fixed points of asymptotically nonexpansive mappings. Bull. Aust. Math Soc. 43, 153-159 (1991)

17. Senter, HF, Dotson, WG: Approximating fixed points of nonexpansive mappings. Proc. Am. Math. Soc. 44(2), 375-380 (1974)

18. Maiti, M, Gosh, MK: Approximating fixed points by Ishikawa iterates. Bull. Aust. Math. Soc. 40, 113-117 (1989)

10.1186/1029-242X-2014-82

Cite this article as: Hou and Du: Convergence theorems of a new iteration for two nonexpansive mappings. Journal of Inequalities and Applications 2014, 2014:82

\section{Submit your manuscript to a SpringerOpen ${ }^{\odot}$ journal and benefit from:}

- Convenient online submission

- Rigorous peer review

- Immediate publication on acceptance

- Open access: articles freely available online

- High visibility within the field

- Retaining the copyright to your article 